\title{
Performative Foreign Language Didactics in Progress: About Still Images and the Teacher as 'Formmeister' (Form Master)
}

\author{
Manfred Schewe \& Fionn Woodhouse
}

\begin{abstract}
This contribution focuses on performative teaching practice. After a brief introduction in which reference is made to an increasing performative orientation in education and the innovative concept of Performative Foreign Language Didactics, the idea of the teacher as 'Formmeister' (Form Master) is presented. The authors then focus on the still image as a concrete example of the wide range of forms that can be derived from the performative arts and gainfully utilised in pedagogical contexts. They outline the general characteristics, function and effect of still images and, via film clips based on their performative teaching practice at University College Cork, demonstrate some of the basic techniques teachers can use to access the different layers of meaning of still images.
\end{abstract}

\section{Introduction}

Please note that a chapter under the same title was first published in a volume edited by Mentz \& Fleiner (2018: 22-42). In this extended version the medium of film has been used to provide vivid demonstrations of the ideas Manfred Schewe presented in the original text. The film clips are based on Fionn Woodhouse's performative practice with Theatre students at University College Cork.

The focus in this contribution is on performative teaching practice. It is not our intention here to chart the complex terrain of 'the performative' in greater detail, but the ideas and references in the following introductory paragraphs might give readers a sense of the position we come from when explicitly focusing on 'still images' and the teacher as 'form master'.

In recentyears we have been witnessing an increasing performative orientation in education. According to Wulf and Zirfas (2007), this development has to be understood from the following perspectives: 
Whoever refers to the Performative today is part of a discourse being established within the social sciences. This discourse brings together the terms 'performative' and 'performance' from linguistics, the term 'performance' from arts and theatre science, and the term 'performativity' from gender studies. Common to all these terms is that they examine occurrences and events on a phenomenological level rather than in terms of their hidden, deeper meaning; they focus on the process rather than on structures and function and, concentrating to a lesser extent on text and symbols, pursue the construction of actuality. The perspective of the performative foregrounds directing and acting practices of social and pedagogical behaviour, their reality-constituting processes, and the correlation of body and language, power and creativity. (Wulf \& Zirfas 2007: 10 , translated by MS)

Readers with a specific interest in how such theoretical perspectives can be related to the area of foreign language education might find it useful to refer to Fleming's (2016) exploration of the term 'performative teaching and learning' and also to other contributions in the volume Performative Teaching, Learning, Research (Even \& Schewe 2016).

As signaled in the title of this paper the concept of Performative Foreign Language Didactics (PFLD) is still very much a work in progress (see e.g., Fleiner 2016; Hallet \& Surkamp 2015). ${ }^{1}$ In an overview article Schewe (2013) offered his perspective on PFLD and, for example, proposed that within PFLD

- the performative arts, particularly the art of theatre, become a central point of reference ${ }^{2}$

- drama and theatre pedagogy be regarded as core disciplines

- in the future 'performative' be used as an umbrella term to describe types of foreign language teaching and learning that derive from the performing arts

- PFLD is critical of the science and business-based models of language teacher education ${ }^{3}$ and directs attention to an alternative arts-based model, by embracing the notion of the foreign language teacher as an artist.

In order to elaborate on this let us tease out the word 'form'.

\footnotetext{
${ }^{1}$ With regard to the German context note the parallel developments in the area of general education. Klepacki \& Zirfas (2013, 181-198) outline their vision of a Performative Didactics.

${ }^{2}$ In this context note that theatre can easily integrate elements from other art forms, for example, dance, music and film.

${ }^{3}$ In this context note for example, Lutzker (2007) who gives a critical account of the science and business-led models as being the dominant perspective in the training of teachers and shaping the entire approach to pre-service and in-service training.
} 


\section{The Teacher as 'Formmeister'}

Language teachers immediately tend to think in terms of 'grammatical form'. The article What comes first in your classes? Form or meaning? by Pouresmaiel and Gholami (2014) might serve as a typical example for the fact that 'form' is often understood as an exclusively linguistic and not as an aesthetic category. In this case it is also somewhat problematic that form and meaning are constructed as opposites.

However, from a performative perspective it is essential that a teacher is critically aware of the mutual relationship between form and content and understands 'form' not exclusively as a linguistic, but also as an aesthetic category, implying the ways in which the body speaks and how sound, word, sentence and movement all interact with each other.

In this context note the following perspective by American scholar Elliot Eisner (2002) who is a fervent advocate of the arts in education:

Another lesson that education can learn from the arts is that the way something is formed matters. We tend in our culture to differentiate between content and form. What is said, for example, is believed to constitute content. How it is said is believed to constitute form. It's all very tidy. However, what is said cannot be neatly separated from how something is said. Form and content interpenetrate. The way in which something is spoken shapes its meaning; form becomes content. Actors have learned this lesson well. So too, have poets, painters and musicians. (Eisner 2002: 197)

Recently Schewe (2014) proposed that the Bauhaus, which is known for the core concept of 'aesthetic synthesis', that is, the integration of all art forms, might be an interesting point of reference for the field of language education. In the Bauhaus the study of form was a central component of the curriculum. The Bauhaus stage featured experiments with form dance, and a number of teachers did not consider themselves to be professors but Formmeister (Form Masters).

Even if the Bauhaus is predominantly associated with the area of Visual Art/Design, the basic concept of a Formmeister (Form Master) might have potential within PFLD. This means that a language teacher would strive to master as best as possible many of the 'artistic forms' through which aesthetic experience can be achieved. A teacher who wishes to apply performative approaches to language, literature and culture, ideally, will have availed of opportunities to gain firsthand experience in the performative arts and, with increasing confidence, will begin to perceive him/herself as a 'teaching artist'. Based on a good understanding of artistic practice s/he will be able to apply or adapt (some of) the forms through which aesthetic experience can also be achieved within a pedagogical context. ${ }^{4}$

\footnotetext{
${ }^{4}$ Regarding the debate focusing on the teacher as artist and the aesthetic dimension of foreign language teaching see e.g., Haack (2010; 2017), Bernstein \& Lerchner (2014), Crutchfield (2015), Fleiner (2016).
} 
Let us illustrate this a bit more by giving a concrete example, that is by focusing on the still image, a form which is typically associated with artistic practice in the theatre. ${ }^{5}$

Anyone who has watched theatre plays will at some point have come across still images. Many performances involve moments in which a character does not move or when a group of characters appear frozen in their position. ${ }^{6}$

A teacher with an explicit interest in theatre might perhaps happen to have read The Caucasian Chalk Circle by Bertolt Brecht and have noted with interest the following stage direction:

Azdak's Judge's seat is in a tavern. Three farmers stand before Azdak. Shauwa brings him wine. In a corner stands an old peasant woman. In the open doorway, and outside, stand villagers and spectators. An Ironshirt stands guard with a banner. (Brecht 1993: 77)

All the characters except one seem to be motionless at the beginning of the scene. This still image will begin to come to life as soon as Shauwa moves towards Azdak and brings him the wine.

In the following stage direction for Scene 32 (THE MURDER) the playwright Peter Weiss actually makes explicit reference to a tableau in the sense of still image ${ }^{7}$ :

CORDAY, suddenly wide awake, raises her arms up and brings the dagger violently down in MARAT's breast. PATIENTS let out one single scream. SADE stands leaning forward, triumphant, shaken by silent laughter. All stand around the bath in a tableau composed as follows: MARAT hangs, as in David's famous picture, with his right arm over the edge of the bath. In his right hand he holds a pen, in his left his papers. CORDAY is still clasping the dagger. The FOUR SINGERS have seized her from behind and forced back her arms until her neckcloth bursts open showing her breast. SIMONNE bends over the bath with an expression of horror. DUPERRET is on his knees. ROUX stands bolt upright on a bench behind the bath. (Weiss 1976: 104-105)

\footnotetext{
${ }^{5}$ Brazilian theatre director Augusto Boal (1931-2009) deserves special credit for paving the way towards using still images in educational contexts through his Theatre of the Oppressed (2008).

${ }^{6}$ Such moments typically occur, for example, in the very visual productions of internationally renowned director Robert Wilson.

${ }^{7}$ Please note that within drama and theatre pedagogy the terms freeze-frame and tableau are often used as equivalents. Freeze-frame would suggest that an image emerges when an action is stopped and the characters freeze in their position. Tableau reminds us of visual art discourse and seems to emphasise more how the elements of a picture are arranged. However, further research is needed to establish the origins of these terms and to what extent they exactly overlap or differ. In this context also note discussions about the development of an international glossary of key terms in the area of 'Performative Arts and Pedagogy' - http: //research.ucc.ie/scenario/2016/02/GLOSSARY/06/en [last accessed December 12, 2017].
} 
Scholars and practitioners in the disciplines of drama and theatre pedagogy, for example Neelands \& Goode (2000); Scheller (2004), have raised an awareness to the wealth of forms which are available in the theatre. However, for language teachers to be in a better position to 'master these forms' and develop their own 'artistic grammar', it is necessary to give a more detailed description of each of these forms, including a more systematic overview of how they can be applied and creatively combined in pedagogical settings.

The following reflections, using the still image form as an example, are to be understood as a first step in this direction. With permission of the students these are accompanied by photographs we took during the academic year 2015/2016 and 2017/18 in our seminars at University College Cork, by film clips and selected students' written responses about their experiences with still images. Extracts from their reflective journals and images are inserted to illustrate further some of the points that are developed in the following sections.

\section{Still Images: General Characteristics}

A still image is the visualisation of an action, that took place, takes place or will take place at a specific moment in time. Characters at this given moment in time demonstrate different postures that were adopted, are adopted or will be adopted respectively. As in a photo or paused film frame, still image characters adopt a certain posture, which includes specific gestures and facial expressions. It is a very simple and controlled form of expression, and, because of its formal clarity and precision, it can have an unusually strong impact on the spectator.

The internationally renowned Chinese artist, $\mathrm{Ai}$ Wei $\mathrm{Wei}^{8}$, for example, whose work can be characterised as a mixture of performance art and photography used the still image form when as a political activist he drew attention to Europe's controversial role in the 'migration crisis'. "Ai Weiwei poses as drowned Syrian infant refugee in 'haunting' photo" reads a caption in one of Britain's leading daily newspapers, THE GUARDIAN.

In pedagogical contexts, a still image can happen spontaneously at any given moment. An example is when the facilitator suddenly interrupts an improvised scene, and the actors freeze in their current pose or action. Alternatively, a still image may be consciously arranged in response to a given task such as: a letter, a word or term, a theme, a picture or a text.

In performative foreign language teaching the facilitator and the course participants have a dramatic spectrum at their disposal, which can be divided into three opposing pairs:

- movement - inaction

- noise - silence

\footnotetext{
${ }^{8}$ For more detailed biographical information see the artist's homepage: https:// aiweiwei.com/index.html [last accessed May 30, 2016].
} 


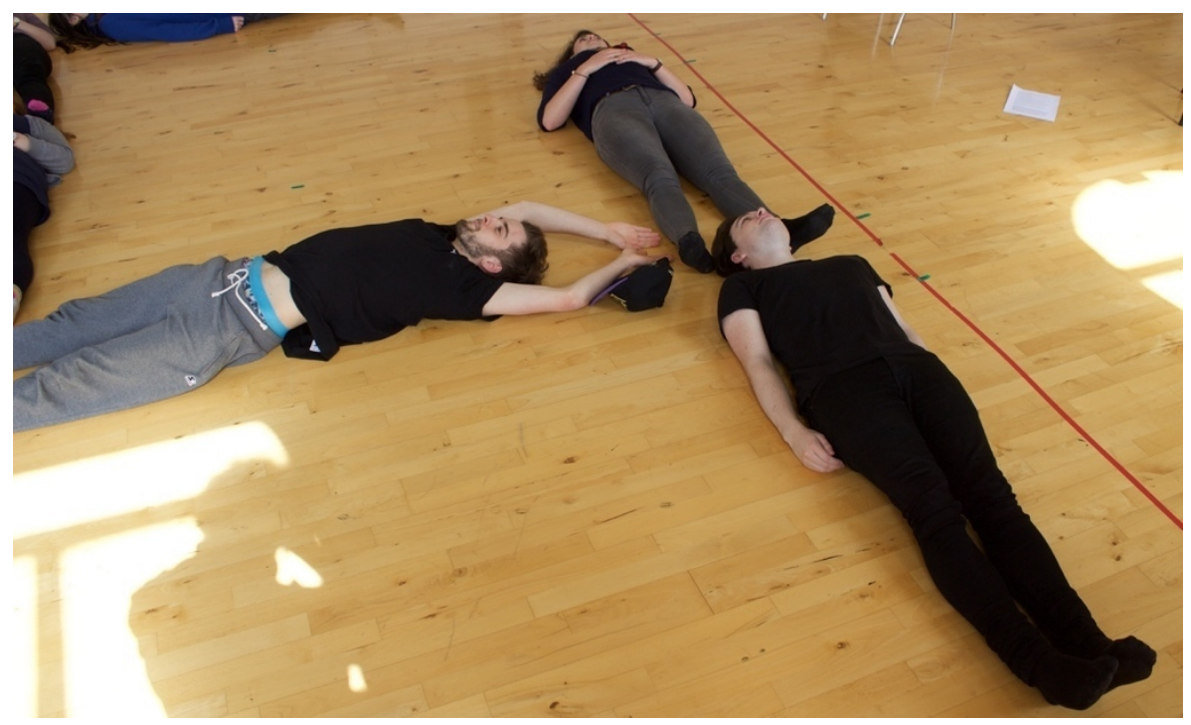

Figure 1: Presenting a still image of the letter ' $T$ ' - Final year students of German in the module Literature and Performance at University College Cork

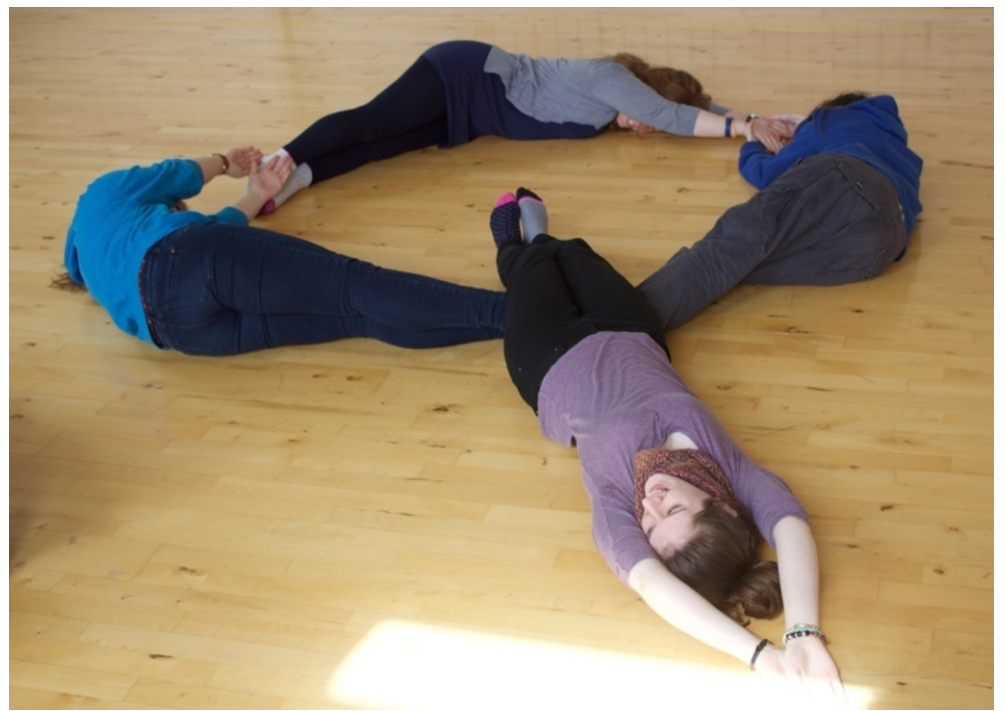

Figure 2: Final year students of German in the module Literature and Performance at University College Cork rehearsing how to form a still image of the letter ' $Q$ ' 
- light - darkness

In the case of still images this spectrum is not completely utilised. The focus is on inaction/silence, merely using the learner bodies, and perhaps also a (significant) object as material. By working within the constraints of this basic means of expression, a high density of meaning is achieved.

A still image allows learners to make a dramatic statement without having to worry about lack of acting ability. While they are momentarily standing in the frame, without verbalising it, they subtly communicate meaning through body language in an effective way. Students learn while forming and presenting a still image, and also, as spectators they interpret the visual signs and the meaning contained in them.

The art of forming a still image is quickly and easily learned. The task of creating a still image is manageable and learners tend to enjoy working towards a visible product. As the competence of the learner increases, the still images become more precise, more accurate and coherent and contain less redundant elements.

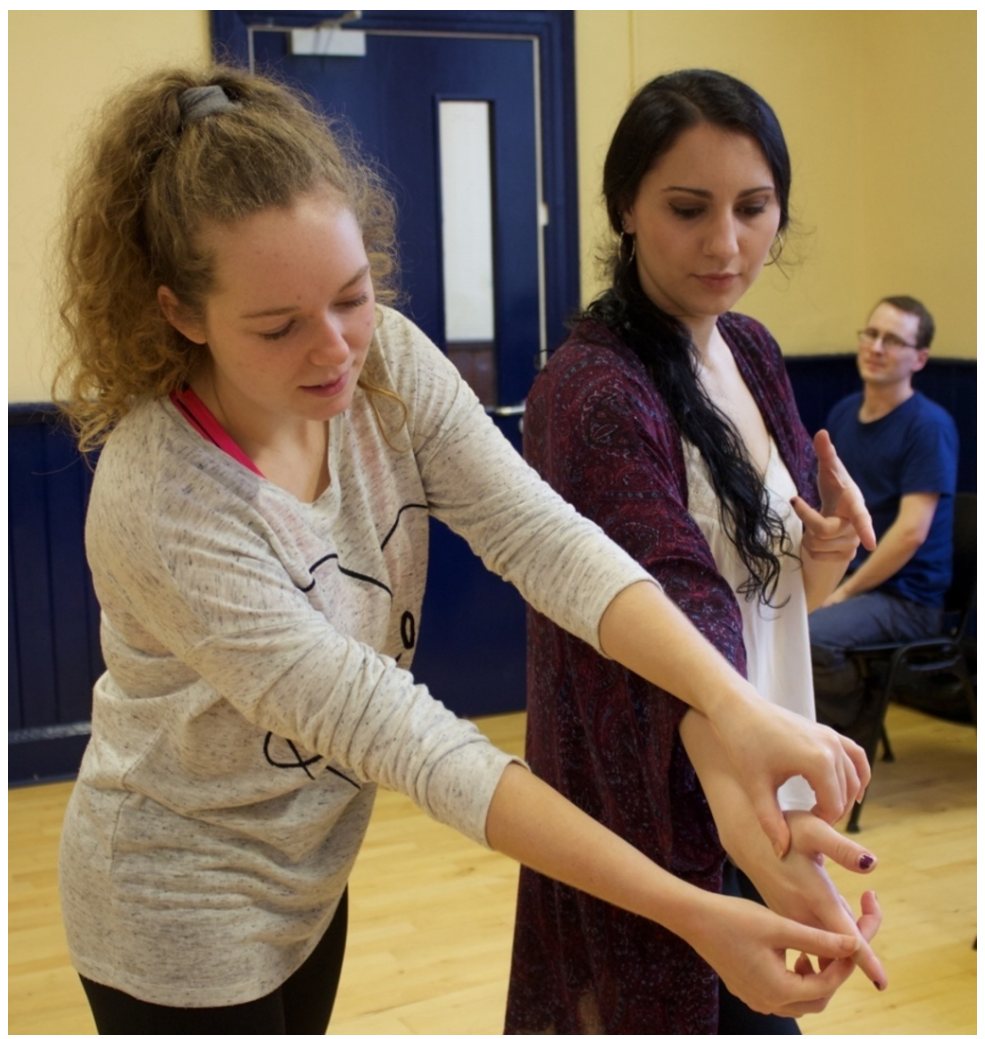

Figure 3: Final year students focusing on still image detail in their Applied Drama \& Theatre module ${ }^{10}$

As it is necessary to be careful and precise, learners may experience some pressure, even more so if they have relatively little time to create the still image.

If, for example, it is a matter of initial clarification of the subject matter, it 
may perhaps be advisable to create a still image in only two minutes. However, a group could also be allowed 20 minutes or more to deepen an aspect of the subject matter through their very concentrated work on a still image.

Usually, it is a good idea to use still images when the facilitator wishes to deliberately slow down the drama lesson, and wishes to draw the attention of learners to a particular context. All of the details of this context, for example, how far each of the characters are standing apart, whether or not they are looking at each other, if particular attention is being paid to an object (and if so which one) become important in order to clarify:

- Which physical posture each character adopts

- What is going through each character's mind

- What relationship exists between the characters and what is their social status

- What specific intentions the characters have.

The reflection process about the still image is sparked off by the learners' subjective interpretations and involves a group discussion which aims at capturing the essence of the image. A significant advantage of this staging technique is that the still image may be revisited at suitable points during a class, seminar or workshop session in order to re-evaluate a specific dramatic context from different perspectives.

In the second semester of the academic year 2015/2016 the still image form was extensively used in a module entitled Literature and Performance. The module description says:

Students will experience how holistic learning methodologies, in particular that of drama in education, can be applied to the study of literary texts from different genres and epochs, including 21st century material. The work will culminate in a performance project involving the participants in the careful planning and rehearsing of a collage of scenes selected from the literary texts studied in more detail as part of this module. ${ }^{11}$

In the work with final year students of German a play was devised which focused on the life and works of Bertolt Brecht. At the end of the semester the play entitled 'Echt Brecht' was performed in front of second year students of German who were studying texts by Bertolt Brecht as part of the module German Literature from the 18th to the 21st century. During the devising process, the students became very familiar with the potential and challenges of the still image form. This is, for example, captured in the text which a student entered into his reflective journal:

\footnotetext{
${ }^{11}$ For the full module description go to: https://www.ucc.ie/modules/descriptions/page032.htm\#GE3145 [last accessed May 30, 2016].
} 
The first few classes saw extensive use of the technique of still images. [...] We applied this technique to various verses of Brecht's Die Legende von der Entstehung des Buches Taoteking auf dem Weg des Laotse in die Emigration in the earlier sessions and included still images in our final performance. One of the aspects of the module I enjoyed the most was interpreting a text and trying to come up with a suitable still-image as quickly as possible. I viewed it as a puzzle we had to solve with our bodies. It's not as easy as it sounds, because you are reduced to the bare minimum of interpretation and physical expression. There is no movement and the concept can be compared to a single frame in a roll of film. Movies play at 35 frames per second, so the progression of images carries the meaning and the one bad frame will hardly be noticed. With still images there is only one opportunity to convey the meaning which makes it much more unforgiving than film. The Brecht still images worked well enough for us, but one group effort I remember was a complete failure and highlighted the importance of clarity in the still image. The class was split in two and both were given a theme, unknown to the other group, to perform. We had the theme 'Germany', and tried to convey an image of the Berlin Wall coming down. It was a hopeless effort - jumbled, unclear and overly complicated. Yes, it made sense to us because we created it, but it made no sense to the other group who only had what they saw in front of them to guide them as to what the meaning was supposed to be. I genuinely felt disappointed that we failed in that exercise and it highlighted to me the importance of clarity and simplicity in any attempt to express an idea, be it through a still-image or otherwise. I found the still-images unexpectedly difficult as they called for tight control of the body and a sharp focussing of the mind. Staying still in one position doesn't come naturally to me as it's not often I stay still in real life (with the possible exception of when I'm sitting on a riverbank somewhere, waiting for a trout to bite). I found it hard to stay still without words, and at times I felt extremely selfconscious and very exposed. After all, I was reduced to an object without words, without personality, and I had no idea as to how I was coming across to the others. I was glad when speech was finally introduced to the still image. In the scenes of the poem we were performing, the lecturer would tap one student on the shoulder, and with that signal the student had to say what they were doing, what they were feeling, in that frozen moment. In a testament to how powerfully the still image can focus the mind, I was surprised to hear words coming from me when I was selected. It was similar to that difficult moment I had when I had to say what Literature meant to me in that the words I was saying seemed to come more from an emotional source rather than an intellectual one. I didn't really think of what I was saying in advance, I had a feeling of what I wanted to be and the words simply seemed to flow from that feeling.

The student continues with some comments that highlight how performative approaches to literature create a special energy and situations in which the students have to think on their feet and learn to react fast by using all their means of expression and, especially, through the medium of the foreign language:

Throughout the module, German was the language mostly used, although 
English wasn't prohibited and was also used at times. The emphasis was on fluency over accuracy and soon we were all using German freely. The dramatic situations of our improvisations called on us to reach for the language needed to keep the drama going: the last thing anyone wanted to do was let the drama die out. If we didn't have the exact words the situation called for, we looked for an alternative way of expressing what we had to act out. I think it would be fair to say that for most of the students in the group, this module was the one where they used the most spoken German. Of the students I knew from other modules, it was impressive to see how comfortable they were using German in comparison to their performance in other modules. Barriers were broken down through the various warm-up exercises and general group dynamic, and students seemed to express themselves more freely in German. The energy created during a Drama class sustained improved communication. There was a lot going on at any moment during our improvisations which highlighted to me how the brain can operate on many different levels at the same time. Not only were we acting, controlling our bodies and voices whilst keeping the context in mind, but simultaneously, we were creating the text extemporaneously. And all of this in German! Without a doubt, Drama is an effective way to get students speaking a foreign language. (Martin Rea)

\section{Function and Effect of Still Images}

The main function of still images is to show actions and poses and thereby symbolically concentrate the meaning that a learner or a group of learners attribute to these actions and poses.

Still images give texts a vivid form: the forming of still images is an act of text interpretation. Not only dramatic texts, but also epic and lyrical texts can be used as a starting point or as a reference point for the creation of still images. Instead of a cognitive text analysis the text is approached using body language, which may initiate a discussion on nuances of meaning. A still image can focus on points of rising or falling tension and specific relationships that become apparent in a literary text.

Photos, paintings and sculptures can be interpreted through still images. To understand more clearly the historical and socio-cultural context, photos from everyday life or photocopies of works of art that represent people in different situations can stimulate the learners' imagination. Still images can become a research tool which helps participants to build (historical) context, for example, when devising a new play.

The meaning contained in abstract terms such as 'fear', 'racism', 'love', 'jealousy' etc. can be demonstrated and understood through still images. For an example of how the abstract term 'Migration Crisis' can be charged with meaning that can be immediately understood see the example from Chinese artist Wei Wei's work above.

Still images can highlight specific points in the development of an action. An example would be the different stages of a cruise. The feelings of the 
passengers or crew are examined at a) the start, b) after 7 days and c) at the end of the journey.

An improvised scene can be created and reflected upon more effectively using still images. Still images can mark or create the beginning and the end of an improvised scene, when an improvised scene is stopped. The facilitator interrupts the improvised scene at an appropriate point, for example immediately before or after a confrontation between two characters, in order to comment on and discuss actions and positions from the inside, that is, from the characters' perspectives, or from the outside, that is, from the observers' perspective. This interruption is unexpected for the characters. When the facilitator interrupts an improvised scene and a still image emerges, this point can become a hinge point, which can lead to a discussion about the details of the still image and, in turn, spark off ideas for how a dramatic scenario might develop further.

As long as care and precision is taken, creating still images can make participants more sensitive to the dramatic art form. Through applying stylised still image technique, learners can experience body language as a subtle means of communication that produces an aesthetic meaning, as it does in theatre.

Still images have both a protective and a controlling function. An example is when a fight between two gangs begins. In order to control the chaos, the facilitator allows the conflict strategies of each gang to be portrayed through still images.

Still images may assist in thematically framing the drama-based lesson more precisely. If a group does not succeed in reaching an agreement on a theme for the teaching session, then it may be useful to change the methodology and try an approach using body language. Instead of conflicted discussions the learners, who are divided into small groups, demonstrate through the creation of still images which aspect of the theme they find interesting. Once still images have been created in a pedagogical setting, how can these become a departure and reference point for a discussion of nuances in meaning? Here are 15 suggestions.

\section{How to access the layers of meaning of still images}

Please note that eleven of the following suggestions are complemented with links to film clips through which vivid demonstrations are given of potential applications of the respective techniques. In order to go directly to a playlist of the eleven clips click here.

\section{A.) Inside Perspectives - from the point of view of the characters in the image}

1. The characters in the still image react to an impulse by the facilitator, for example, a light tap on the shoulder, and express their present thoughts and feelings one after the other. 
2. The characters in the still image are specifically asked questions by individual observers, whereby the characters may be instructed only to answer with YES or NO.

3. The still image is commented on from the perspective of one of the characters.

4. The participants present their still image with a carefully chosen caption (spoken, written, projected), thus capturing its essence for the observing participants.

5. A text, for example a personal letter, is read out atmospherically by a group spokesperson. During the reading, at previously agreed points, the other group members form a still image. Coupling text and image in this way can strengthen the impact the reading has on the observing participants.

6. The individual images become reference points for showing differing opinions, highlighting changing emotions/status/situations or a (devised) story. Participants present a series of still images choosing the order of, and carefully choreographing transitions between, the images.

7. The still image creator explains what $\mathrm{s} /$ he wanted to express through the still image.

8. In order to show how they have perceived a situation to be, or what situation they imagined, one of the participants chooses other group participants to form a still image.

9. A participant forms a still image and integrates him/herself into the still image (inside perspective). S/he then steps out of the image, asks another participant or the facilitator to take his/her place. The participant then explains his/her interpretation of the image (outside perspective).

10. The still image is brought to life. The characters continue with the interrupted action, possibly in slow motion.

B) Outside Perspectives - from the point of view of observing participants/facilitator

1. The observers comment from their seats on what impact the still image has on them.

2. The observers imitate the pose, facial expression and gestures of the characters in the still image in order to obtain a feeling for the characters' thoughts, and the observers' assumed thoughts are spoken aloud.

3. An observer stands behind the respective still image character and taps him/her on the shoulder. Speaking in the first person, the observer articulates what the character is thinking or feeling at that moment. 
4. Observers stand behind a character in the still image and begin a verbal interaction which, in their view, captures the essence of the situation portrayed in the still image.

5. The facilitator engages in a role dialogue with the characters. In doing so, s/he confronts or provokes them and each character has to react spontaneously in role.

To further explore the range of applications of still images the following extract from a student's learning journal highlights how using still image aids in distilling and understanding complex topics. Note that instead of directly engaging the students in a discussion of Jonathan Levy's (2005) eleven rationales for 'How the Theatre teaches', they were allocated selected rationales and asked to present these in the form of still images. The group of students in image 4 focused on the sixth rationale: "the theatre teaches by conveying information vividly" (Levy 2005: 23).

Creating our still images meant fundamentally first understanding the rationales in order to create still images that summed up their content. Creating a still image instils its meaning in our bodies as well as our minds.

(Maxine Carey-Acton)

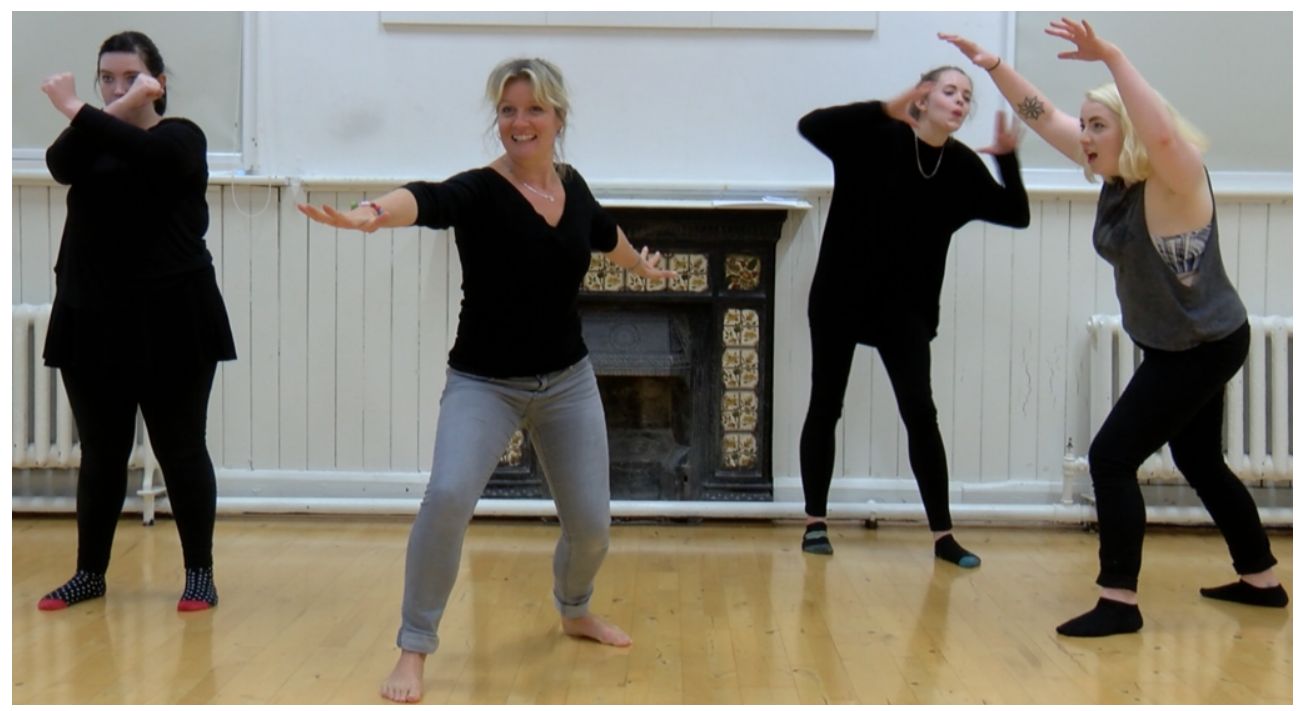

Figure 4: Applied Drama \& Theatre students use still image to illustrate Jonathan Levy's (2005) sixth rationale of 'How the Theatre Teaches'

Using this image (4) as a concrete example, some of the techniques listed above could be used to access its layers of meaning: As in suggestion 1 above, the facilitator taps the characters on the shoulder to hear their thoughts. The central character may respond with 'I am really enjoying surfing without a care 
in the world', the character on the far right may respond with 'The wind has made me the biggest wave and I'm going to crash into this little surfer!'

As in suggestion 11 above, an observer (audience member) describes what $\mathrm{s} /$ he sees in the still image: 'I see a person on the left making an $\mathrm{X}$ sign, this could be a letter or could have a meaning like no or stop? I see a person in the middle who is surfing and really enjoying themselves. I'm worried that the person/thing/shark on the left is going to get the surfer - I want to help them, to tell them to watch out and be careful.'

As in suggestion 4 above, a title is given to the still image. The title selected is 'Do not surf when it is very windy!'

The following excerpt from a reflective journal shows that working with still images can be a very rewarding experience for students. What is experienced in a seminar setting is transferred to the student's experience in daily life:

My favourite part of the module was the introduction of the still image technique which was used in nearly every class throughout the module, and even in the actual performance. I found the use of the still image technique to be a very interesting learning experience. Living in a world where there is always noise or something in movement to explain an action, a frozen image can be quite hard to decipher at times. An excellent example was in a class when we began to build a still image, in groups of three. My group began with a statue of Hercules. This, we explained, was a symbol of strength, courage and honour, someone or something that has no fear. We were then asked to build upon this image. We did this by placing someone cowering behind the powerful Hercules. When we first allowed the others in the class to comment upon it, they came to the conclusion that the Hercules-like figure was protecting us from an evil creature. However, our original interpretation was that Hercules was trying to protect us from our own inner demons. The varying interpretations of the image that they came up with really got me thinking about how we often form impressions based on snapshots of other people's lives. Every single day we are bombarded with thousands upon thousands of images, each of which is interpreted slightly differently by everyone. Whether these be in advertisements, television, on social media, or simply seeing a single image of person's day as they walk past you on the street. It made me ask myself lots of different questions the models in those ads or the actors on our screen - how many times did they have to take the same shot again and again until they found the perfect one? The people on our social media - are they really this happy in life, or are they hiding behind their Facebook façade? The woman who passed me on the street with a thoughtful look on her face - what could have possibly been going through her head? Is there something big happening in her life, or is she simply trying to remember what she has in the cupboards for dinner tonight? These are literally only snapshots into her life, a life that I will never fully understand and more than likely never be involved in. But I can't help but wonder about them all as I continue on my day. (Orla Hill)

As mentioned above, our reflections are only a first step towards tapping into the 
rich teaching and learning potential of still images. ${ }^{12}$ Still images are just one example of the wide range of forms that can be derived from the performative arts and gainfully utilised in pedagogical contexts. It would be desirable that in years to come more systematic descriptions of these forms become available so that teachers who ideally have experienced these forms in a special training course, can apply performative approaches to language, literature and culture with confidence. Given the fact that Performative Foreign Language Didactics places special emphasis on physicality and movement in space, the potential of the new media should be explored more to capture the essence of 'artistic forms' and provide vivid demonstrations of how these can be creatively combined and applied in pedagogical settings. We hope that the film clips we have provided will be regarded as a promising step in this direction and encourage applied theatre colleagues to experiment with showcasing their performative teaching practice in a similar fashion. ${ }^{13}$

\section{Bibliography}

Boal, Augusto (2008): Theatre of the Oppressed. Chicago: University of Chicago Press

Bernstein, Nils \& Lerchner, Charlotte (eds.) (2014): Ästhetisches Lernen im DaF-/DaZ-Unterricht: Literatur - Theater - Bildende Kunst - Musik - Film. Göttingen: Universitätsverlag (= Materialien Deutsch als Fremdsprache, Band 93)

Brecht, Bertolt (1993): The Caucasian Chalk Circle. London: Methuen Drama Crutchfield, John (2015): Fear and Trembling. In: Scenario IX/2, 114-128. Online:

http://research.ucc.ie/scenario/2015/02/Crutchfield/07/en; [last accessed February 20, 2016]

Eisner, Elliot W. (2002): The Arts and the Creation of Mind. New Haven \& London: Yale University Press

Even, Susanne \& Schewe, Manfred (eds.) (2016): Performatives Lehren, Lernen, Forschen - Performative Teaching, Learning, Research. Berlin: Schibri

Fleiner, Micha (2016): Performancekünste im Hochschulstudium: Transversale Sprach-, Literatur- und Kulturerfahrungen in der fremdsprachlichen Lehrerbildung. Berlin/Milow: Schibri

\footnotetext{
12 Note also the potential of still images in the context of Enquiry-Based Learning using Scenic Play as a Medium and Method of Qualitative Research (Nitsch \& Scheller 2016).

${ }^{13}$ Note e.g. the short filmic demonstrations on the following website: http:// www.bbc.co.uk/schools/gcsebitesize/drama/exploring/explorativ_strategies rev1.shtml [last accessed May 30, 2016]. Reference is also made on this site to other performative 'strategies', including hot seating, narration, marking the moment, forum theatre.
} 
Fleming, Michael (2016): Exploring the Concept of Performative Teaching and Learning. In: Even, Susanne \& Schewe, Manfred (eds.): Performatives Lehren, Lernen, Forschen - Performative Teaching, Learning, Research. Berlin: Schibri, 189-205

Haack, Adrian (2017): Dramapädagogik, Selbstkompetenz und Professionalisierung. Performative Identitätsarbeit im Lehramtsstudium Englisch. Stuttgart: Metzler

Haack, Adrian (2010): 'KünstlerInnen der improvisierten Aufführung'. Performative Fremdsprachendidaktik als Teil des Lehramtsstudiums. In: Scenario IV/1, 18-54. Online: http://research.ucc.ie/scenario/2010/01/haack/04/de [last accessed February 20, 2016]

Hallet, Wolfgang \& Surkamp, Carola (eds.) (2015): Dramendidaktik und Dramapädagogik im Fremdsprachenunterricht. Trier: Wissenschaftlicher Verlag

Klepacki, Leopold \& Zirfas, Jörg (eds.) (2013): Theatrale Didaktik. Ein pädagogischer Grundriss des schulischen Theaterunterrichts. Weinheim and Basel: Beltz Juventa

Levy, Jonathan (2005): Reflections on How the Theatre Teaches. In: Journal of Aesthetic Education 39/4, 20-30

Lutzker, Peter (2007): The Art of Foreign Language Teaching. Improvisation and Drama in Teacher Development and Language Learning. Tübingen: Narr Francke Attempto

Neelands, Jonothan \& Goode, Tony (2000): Structuring Drama Work. A handbook of available forms in theatre and drama. Cambridge: University Press

Nitsch, Wolfgang \& Scheller, Ingo (2016): Enquiry-Based Learning using Scenic Play as a Medium and Method of Qualitative Research. In: Even, Susanne \& Schewe, Manfred (eds.): Performatives Lehren, Lernen, Forschen - Performative Teaching, Learning, Research. Berlin: Schibri, 280-300.

Pouresmaiel, Amin \& Gholami, Javad (2014): What comes first in your classes? Form or meaning! In: Humanising Language Teaching 16/3. Online: http://www.

hltmag.co.uk/jun14/mart06.htm [last accessed May 17, 2016].

Scheller, Ingo (2004): Szenische Interpretation. Theorie und Praxis eines handlungs- und erfahrungsbezogenen Literaturunterrichts in Sekundarstufe I und II. Seelze-Velber: Kallmeyersche Verlagsbuchhandlung

Schewe, Manfred (2014): Für das Ästhetische einen Ort schaffen. DaF als Bauhaus - ein Vorentwurf. In: Bernstein, Nils \& Lerchner, Charlotte (eds.) (2014): Ästhetisches Lernen im DaF-/DaZ-Unterricht: Literatur - Theater Bildende Kunst - Musik - Film. Göttingen: Universitätsverlag, 167-177 (= Materialien Deutsch als Fremdsprache, Band 93) 
Schewe, Manfred (2013): Taking Stock and Looking Ahead: Drama Pedagogy as a Gateway to a Performative Teaching and Learning Culture. In: Scenario VII/1, 5-27. Online:

http://research.ucc.ie/scenario/2013/01/Schewe/02/en [last accessed May 17, 2016]

Weiss, Peter (1976): The Persecution and Assassination of Marat as Performed by the Inmates of the Asylum of Charenton under the Direction of the Marquis de Sade. London: Calder \& Boyars Ltd.

Wulf, Christoph \& Zirfas, Jörg (eds.) (2007): Pädagogik des Performativen. Theorien, Methoden, Perspektiven. Weinheim and Basel: Beltz 